\title{
A feasibility test of CMT inversion using regional network of broad-band strong-motion seismographs for near-distance large earthquakes
}

\author{
Ikuo Cho ${ }^{1 *}$, Ichiro Nakanishi ${ }^{2}$, and Tamao Sato $^{3}$ \\ ${ }^{1}$ Division of Earth and Planetary Sciences, Graduate School of Science, Hokkaido University, Sapporo, Japan \\ ${ }^{2}$ Department of Geophysics, Kyoto University, Kyoto, Japan \\ ${ }^{3}$ Department of Earth and Environmental Sciences, Hirosaki University, Hirosaki, Japan
}

(Received April 27, 1998; Revised March 18, 1999; Accepted March 24, 1999)

\begin{abstract}
When a large earthquake occurs in and around the Japanese Islands, we should immediately determine the size and the fault geometry of the earthquake to mitigate earthquake disasters. Broad-band, strong-motion data of neardistance large earthquakes are used to investigate the possibility of CMT inversion. We perform a moment tensor inversion using the data sets of the 1993 Hokkaido Nansei-oki earthquake $\left(\mathrm{M}_{\mathrm{JMA}_{\mathrm{A}}}\right.$ 7.8), the 1994 Hokkaido Toho-oki earthquake ( $\mathrm{M}_{\mathrm{JMA}}$ 8.1) and the 1994 Sanriku Haruka-oki earthquake ( $\mathrm{M}_{\mathrm{JMA}}$ 7.5). The accuracy of the solutions is examined by comparison with the solutions derived from global data sets, which reveals that the mechanism and moment magnitude are quite adequate for the purpose. Numerical experiments are made to analyze the influence of the source finiteness on the solutions. The numerical experiments suggest that the influence of the source finiteness on the mechanism retrieval is smaller than that on the moment retrieval. We suggest the installation of a network system of broad-band, strong-motion seismographs in the Japanese Islands.
\end{abstract}

\section{Introduction}

The Japanese Islands have experienced many destructive earthquake disasters. Shallow inland earthquakes generally cause disasters when their magnitudes exceed a value of about 6. Nearby oceanic earthquakes cause destructive tsunamis when they are larger than a magnitude of about 7 (Usami, 1996). When a large earthquake occurs in and around the Japanese Islands, we should immediately determine the location, the size and the fault geometry of the earthquake to mitigate the disasters.

Dziewonski et al. (1981) suggest a Centroid Moment Tensor (CMT) inversion of global seismological data. We can simultaneously estimate an earthquake location and the fault geometry by this inversion method. The CMT inversion has been accepted as fundamental to determine the dominant characteristics of earthquake sources. However, it is a relatively time-consuming process to mitigate earthquake disasters. Long time is spent in preparing the data sets, since teleseismic long-period waveforms are used for the CMT inversion. If we use long-period body-wave data recorded in the Japanese Islands, the CMT inversion can be done within quite short time.

Very broad-band, seismological observations by STS-1 seismographs (Wielandt and Streckeisen, 1982; Wielandt and Steim, 1986) have been established in the Japanese Islands (Fukushima et al., 1988, 1989; Yamada et al., 1989). We can use the waveform data in a CMT inversion. The disadvantage of the use of the STS-1 is that the response of

*Now at Department of Geophysics, Kyoto University, Kyoto, Japan. the seismograph to the velocity can reach the value of only about $0.01 \mathrm{~m} / \mathrm{s}$. This velocity of $0.01 \mathrm{~m} / \mathrm{s}$ approximately corresponds to the seismic intensity of 2 in the JMA (Japan Meteorological Agency) scale (JMA, 1996). Several networks of strong-motion seismographs have been installed recently (Kinoshita, 1998; Kinoshita et al., 1997; Noda and Kano, 1993). The dynamic ranges are sufficiently wide, but the seismographs do not cover the long-period range necessary for the CMT inversion. It has been suggested that a network of broad-band strong-motion seismographs in the Japanese Islands is necessary to mitigate disasters caused by near-distance large earthquakes (Fukushima et al., 1987, 1988, 1989; Hanakago et al., 1990; Nakanishi et al., 1991).

The aim of this study is to investigate the possibility of CMT inversion, using broad-band strong-motion data of near-distance large earthquakes. We examine the accuracy of the solutions by the comparison with the solutions derived from global data sets. The influences of the source finiteness on the solutions are analyzed by numerical experiments.

\section{Strong-Motion Data}

The Kanto earthquake of September 1, 1923 (M JMA $_{\text {7.9) }}$ overtook the Kanto region, central Japan, and caused more than 240,000 casualties. Tsunami, landslides and, in particular, the fire following the earthquake increased the damage. Figure 1 shows the seismic intensity distribution reported by JMA. The seismic intensity scale is explained in Table 1. We find from this figure that the seismographs installed for a CMT inversion in the Japanese Islands must be characterized by both a wide period range and a wide dynamic range. Thus, only broad-band, strong-motion seismographs can provide us with the regional and long-period data for the CMT inversion. 
Table 1. Explanation table of JMA seismic intensity scale.

\begin{tabular}{|c|c|c|}
\hline Scale & People & Outdoor situations \\
\hline 0 & Imperceptible to people. & \\
\hline 1 & Felt by only some people in buildings. & \\
\hline 2 & $\begin{array}{l}\text { Felt by most people in buildings. } \\
\text { Some people awake. }\end{array}$ & \\
\hline 3 & $\begin{array}{l}\text { Felt by most people in buildings. } \\
\text { Some people are frightened. }\end{array}$ & Electric wires swing slightly. \\
\hline 4 & $\begin{array}{l}\text { Many people are frightened. } \\
\text { Some people try to escape from danger. } \\
\text { Most sleeping people awake. }\end{array}$ & $\begin{array}{l}\text { Electric wires swing considerably. People } \\
\text { walking on the street and some people driving } \\
\text { automobiles notice the tremor. }\end{array}$ \\
\hline 5 Lower & $\begin{array}{l}\text { Most people try to escape from danger. } \\
\text { Some people find it difficult to move. }\end{array}$ & People notice electric-light poles swing. \\
\hline Upper & $\begin{array}{l}\text { Many people are considerably frightened } \\
\text { and find it difficult to move. }\end{array}$ & $\begin{array}{l}\text { Unreinforced concrete-block walls collapse } \\
\text { and tombstones overturn. }\end{array}$ \\
\hline 6 Lower & Difficult to keep standing. & $\begin{array}{l}\text { In some buildings, wall tiles and windowpanes } \\
\text { are damaged and fall. }\end{array}$ \\
\hline Upper & $\begin{array}{l}\text { Impossible to keep standing and } \\
\text { to move without crawling. }\end{array}$ & $\begin{array}{l}\text { In many buildings, wall tiles and windowpanes } \\
\text { are damaged and fall. }\end{array}$ \\
\hline 7 & $\begin{array}{l}\text { Thrown by the shaking and impossible } \\
\text { to move at will. }\end{array}$ & $\begin{array}{l}\text { In most buildings, wall tiles and windowpanes } \\
\text { are damaged and fall. }\end{array}$ \\
\hline
\end{tabular}

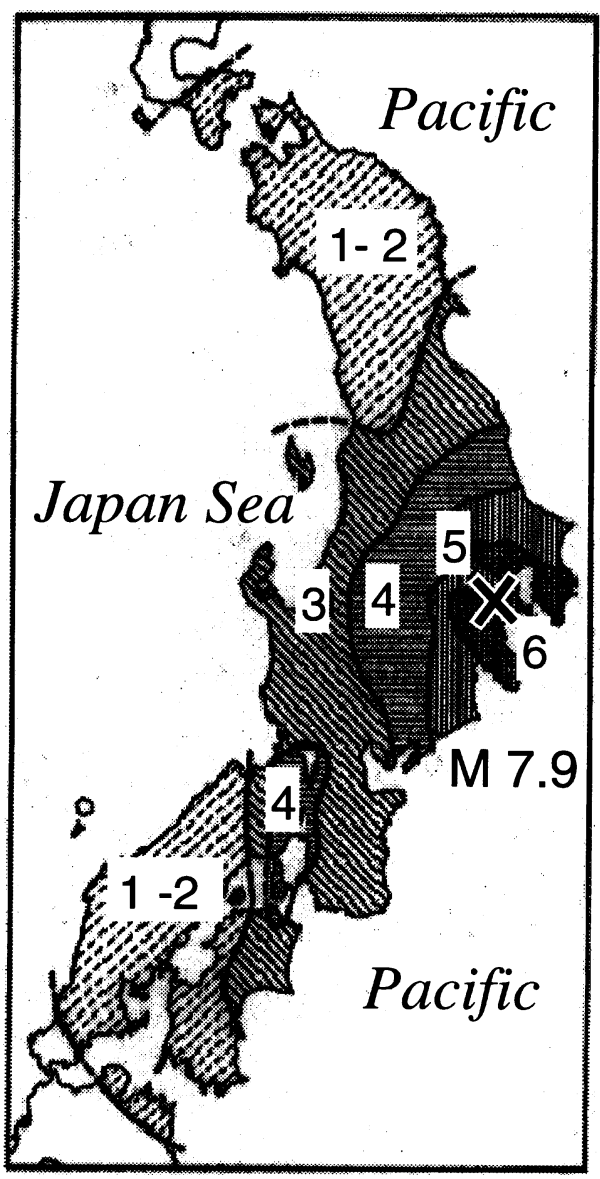

Fig. 1. Map showing the seismic intensity distribution by the 1923 Kanto earthquake. The map is based on the figure 430-1 of Usami (1996).
We analyze the following recent destructive earthquakes: the 1993 Hokkaido Nansei-oki earthquake (M JMA $_{\text {7.8), the }}$ 1994 Hokkaido Toho-oki earthquake ( $\mathrm{M}_{\mathrm{JMA}}$ 8.1) and the 1994 Sanriku Haruka-oki earthquake ( $\mathrm{M}_{\mathrm{JMA}}$ 7.5). Figure 2 shows the seismic intensity distributions on the JMA scale for the three earthquakes. The epicenters and the observation locations are also shown in Fig. 2. We currently have no network system of broad-band strong-motion seismographs in the Japanese Islands. We use the data recorded at stations MMA $\left(41.16^{\circ} \mathrm{N}, 140.44^{\circ} \mathrm{E}\right)$ and TMR $\left(41.10^{\circ} \mathrm{N}, 141.39^{\circ} \mathrm{E}\right)$ of the Hirosaki University which are located on the northern edge of the main land (Honshu) of Japan. The seismic intensities of 3 to 5 are estimated for TMR and MMA. Each station is equipped with broad-band, strong-motion VS3 seismographs (Muramatsu, 1995). The response is flat to velocity in a period range from 0.05 to $600 \mathrm{~s}$. The seismograph can record velocities from $5 \times 10^{-7}$ to $1 \mathrm{~m} / \mathrm{s}$. The velocity of $1 \mathrm{~m} / \mathrm{s}$ approximately corresponds to a seismic intensity of 7 on the JMA scale.

We use the velocity waveforms with a duration of $10 \mathrm{~min}$ from the origin time. The records are band-pass filtered with a period range from 70 to $360 \mathrm{~s}$ and resampled at a uniform interval of $10 \mathrm{~s}$. We use the NS and the UD components of TMR for the 1993 Hokkaido earthquake, the three components of MMA and the NS and UD components of TMR for the 1994 Hokkaido earthquake, and the three components of TMR for the 1994 Sanriku earthquake.

\section{Linear Moment Tensor Inversion}

If we simultaneously derive a centroid location and the centroid moment tensor, the inverse problem becomes nonlinear. We usually adopt an iteration technique, where starting source parameters are iteratively refined and convergence 


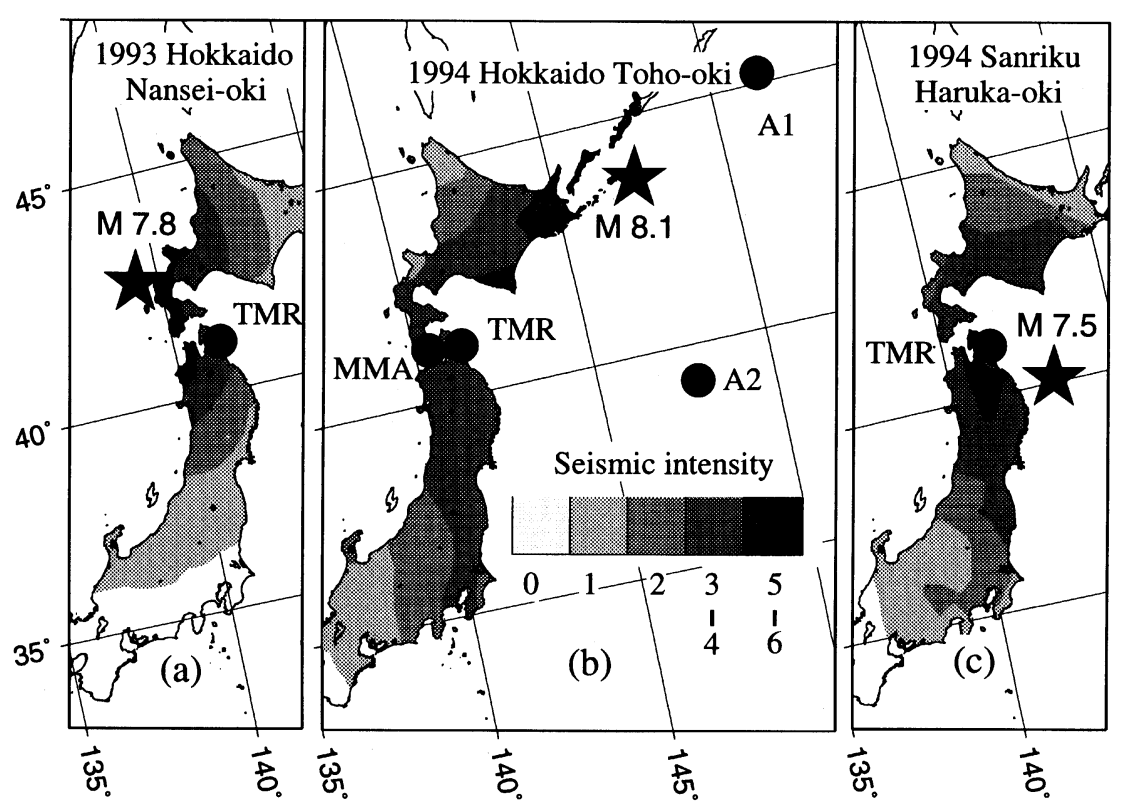

Fig. 2. Maps showing the seismic intensity distributions. The epicenters and the observation stations are also shown with solid stars and circles, respectively. (a) Hokkaido Nansei-oki earthquake of July 12, 1993. (b) Hokkaido Toho-oki earthquake of October 4, 1994 . A1 and A2 are hypothetical stations for the numerical experiments. (c) Sanriku Haruka-oki earthquake of December 28, 1994.

Table 2. Event locations.

\begin{tabular}{|c|c|c|}
\hline Event & Origin time (GMT) & Location \\
\hline 1993 Hokkaido $^{3}$ & 13:17, July 12,1993 & $42.76^{\circ} \mathrm{N}, 139.32^{\circ} \mathrm{E}, 25 \mathrm{~km}$ \\
\hline 1994 Hokkaido $^{1}$ & 13:23, October 4, 1994 & $42.00^{\circ} \mathrm{N}, 148.00^{\circ} \mathrm{E}, 42 \mathrm{~km}$ \\
\hline 1994 Sanriku$^{2}$ & 12:19, December 28, 1994 & $41.00^{\circ} \mathrm{N}, 143.02^{\circ} \mathrm{E}, 10 \mathrm{~km}$ \\
\hline
\end{tabular}

to the best fitting source parameters is achieved within a finite iteration. The problem with this method is that inappropriate starting parameters can easily lead to divergence or incorrect solutions when the station coverage is insufficient.

To simplify the inverse problem, we fix the event location. The event locations are shown in Table 2. We use a linear moment tensor inversion based on a normal mode theory (Gilbert and Dziewonski, 1975), and the eigenperiods $(T>45 \mathrm{~s})$ and associated eigenfunctions calculated for earth model 1066A (Gilbert and Dziewonski, 1975) by Buland and Gilbert (1976). The $k$-th record of ground motions excited by a point source is expressed as

$$
U_{k}(\mathbf{X}, t)=\sum_{j=1}^{6} A_{k j}\left(\mathbf{X}, \mathbf{X}_{\mathbf{s}}, t\right) f_{j},
$$

where $A_{k j}$ are the excitation kernels, $\mathbf{X}$ the receiver location, $\mathbf{X}_{\mathbf{S}}$ the source location, and $f_{j}$ the six independent elements of the moment tensor. Equation (1) is solved by a least squares method. We assume that the trace of the moment tensor vanishes. Thus we have five independent parameters.

We compare the solutions of this study with the solutions derived by Harvard group. The parameters of the best double couple (Dziewonski and Woodhouse, 1983) and the Compensated Linear Vector Dipole (CLVD) (Knopoff and Randall, 1970) are shown in Fig. 3. The moment release of this study is 2.4 times as large as that found by the Harvard group for the 1993 Hokkaido earthquake, while the moment release of this study and Harvard group is almost the same for the 1994 Sanriku earthquake. The CLVD components found in this study are significantly scalar large. Though the marked discrepancies are found in the moment release and the CLVD, the moment magnitudes and the mechanism solutions of this study and the Harvard group are fairly consistent with each other. Therefore, we consider our estimates of the mechanism and size to be quite adequate and can be used for earthquake countermeasures.

Figure 4 shows an example of the comparison between the observed and synthetic seismograms for the 1994 Hokkaido earthquake. The synthetic waveforms match the observations fairly well except for the UD component of TMR. We suspect that a short-period atmospheric disturbance or an instrumental problem is the most plausible cause. The synthetics of the 1993 Hokkaido earthquake and the 1994 Sanriku 


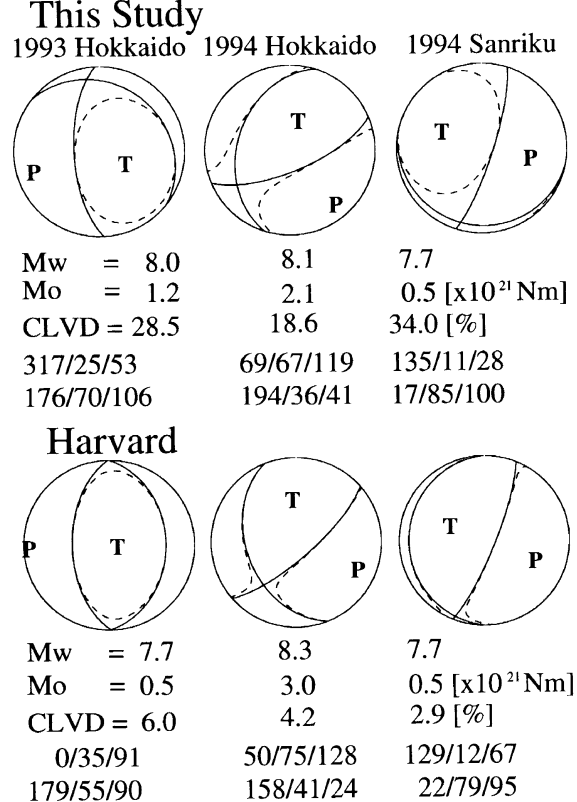

Fig. 3. Comparison of the moment tensor solutions of this study and Harvard group (Dziewonski et al., 1994, 1995). The broken lines and solid lines correspond to the moment tensor and the best double couple, respectively. Equal area projection of the lower hemisphere is used.

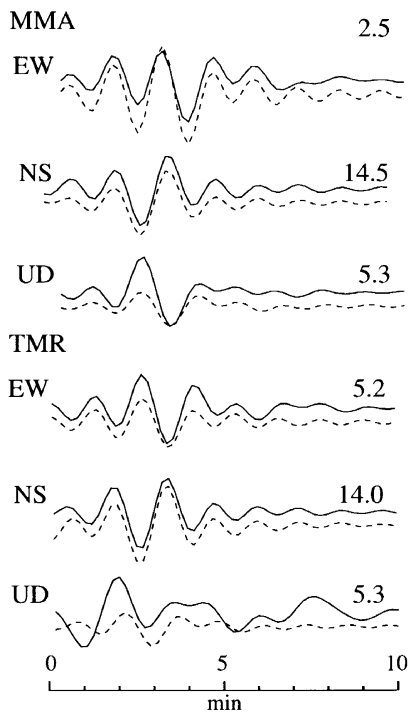

Fig. 4. Comparison of the observed (solid line) and synthetic seismograms (broken line) for the 1994 Hokkaido earthquake. The peak amplitude of the observed record (in $10^{-4} \mathrm{~m} / \mathrm{s}$ unit) is given on the right of each trace.

earthquake explain the observations well.

\section{Influence of Earthquake Location on the Inver- sion}

We are required to respond quickly to large earthquakes, and have only a short time to make the location of the centroid. Nakanishi et al. (1991) used a hypocenter as the centroid in the long-period $(T>70 \mathrm{~s})$ moment tensor inversion of near-field, moderate to large earthquakes $\left(\mathrm{M}_{\mathrm{w}} \leq 7.2\right)$.

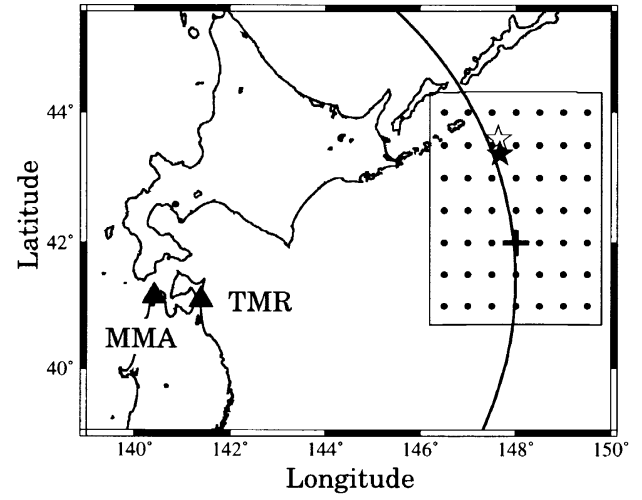

Fig. 5. Geometry of the grid points assumed to be the centroid (solid circles). The epicenter reported by JMA (JMA, 1995) $\left(43.37^{\circ} \mathrm{N}, 147.67^{\circ} \mathrm{E}, 30\right.$ $\mathrm{km}$ ) (black star), the centroid found by Harvard group (Dziewonski et al., 1995) $\left(43.6^{\circ} \mathrm{N}, 147.6^{\circ}, 68 \mathrm{~km}\right)$ (white star) and the best location of the centroid found in this study $\left(42.0^{\circ} \mathrm{N}, 148.0^{\circ} \mathrm{E}, 45 \mathrm{~km}\right)$ (cross) are also shown in the figure. The arc is a part of circle with the center at MMA and a radius of $5.7^{\circ}$

The use of a hypocenter as a centroid does not seem to influence the inversion significantly when using long-period data. Hypocentral parameters reported by JMA, where the units of the latitude, the longitude and the depth are $0.1^{\circ}, 0.1^{\circ}$ and $10 \mathrm{~km}$, respectively, are available by E-mail right after an earthquake.

We investigate the influence of earthquake location on the moment tensor inversion, using the 1994 Hokkaido earthquake that is the largest among the three earthquakes. We set grid points at an interval of $0.5^{\circ}, 0.5^{\circ}$ and $20 \mathrm{~km}$ in the direction of the latitude, the longitude and the depth, respectively. The geometry of the grid points is shown in Fig. 5. At each grid point we make the same inversion as made in the above analysis, assuming the grid point to be the centroid. We define the best location of the centroid as the location minimizing the RMS residual. As a result the centroid is located about $150 \mathrm{~km}$ to the south of the hypocenter reported by JMA and the centroid found by the Harvard group. It should be noticed that the JMA hypocenter and the centroid found in this study are located at almost the same distance from the stations of MMA and TMR as indicated by the arc in Fig. 5.

Figure 6 shows the inversion results in detail. Since the residual takes the smallest value at the depth of $45 \mathrm{~km}$, we examine the results at the depth of $45 \mathrm{~km}$ at this time. The variations in the mechanism, in the residual and in the moment magnitude are very slight along the arc shown in Fig. 5, and the residuals are small along the arc. Systematic changes in mechanism are found in the direction from the station to the grid point. The mechanism is significantly influenced by phase shifts of the waveforms.

Figure 7 shows the dependency of the mechanism and the residual on the depth of the hypocenter and the centroid found in this study. Though the depths of the smallest residual do not agree with each other, the variations in the mechanism are small in a wide depth range and the mechanisms are very similar between both locations. The corresponding moment magnitudes show a slight change, ranging from 8.0 to 8.2 . 

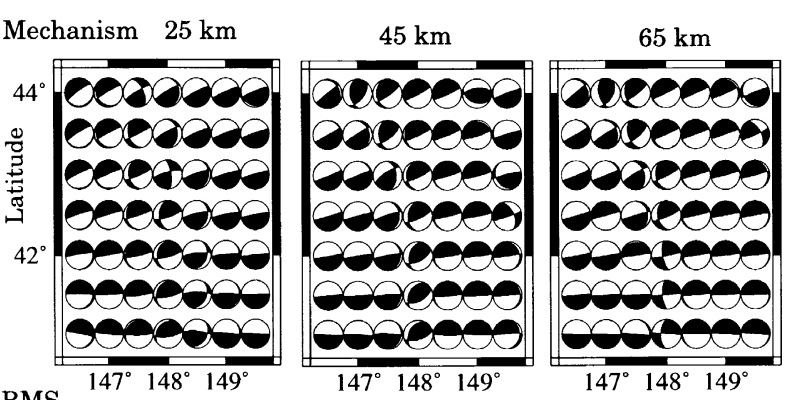

RMS
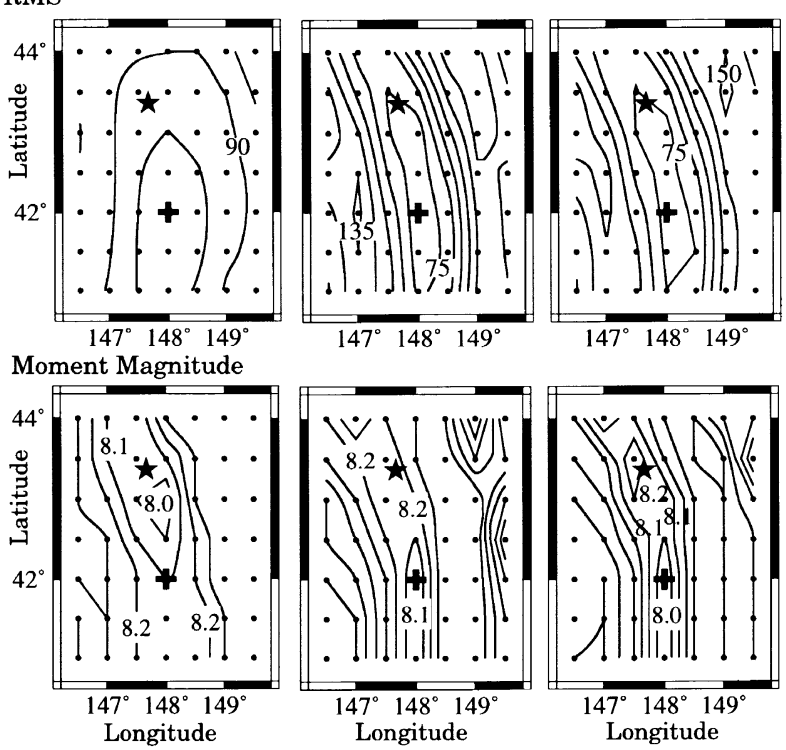

Fig. 6. Results of the inversion: The best double couple mechanism (top), the RMS (in $10^{-11} \mathrm{~m}^{2} / \mathrm{s}^{3}$ unit) (middle) and the moment magnitude (bottom). Each map corresponds to the frame in Fig. 5. A black star and a cross show the epicenter reported by JMA and the centroids found in this study, respectively.

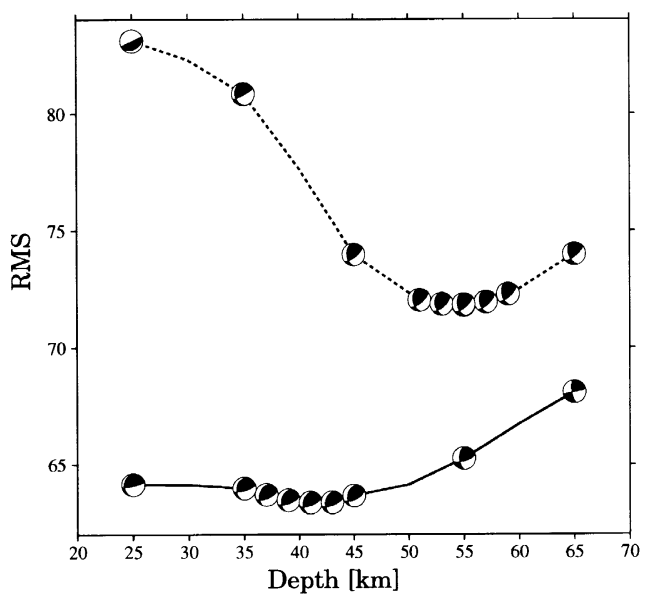

Fig. 7. Dependence of the mechanism and the RMS residual (in $10^{-11}$ $\mathrm{m}^{2} / \mathrm{s}^{3}$ unit) on the depth of the hypocenter (broken line) and the centroid found in this study (solid line).

These facts imply that the present inversion allows an ambiguity in the depth. We conclude that the mechanism and the moment magnitude of the 1994 Hokkaido earthquake are accurately obtained by using the hypocenter as the centroid. The insufficient station coverage would contribute largely to the discrepancy in location between the hypocenter and the centroid.

\section{Numerical Experiments}

When we use regional data sets, moment tensor solutions are unfavorably influenced by source finiteness. The influences can be investigated by numerical experiments. We briefly describe the numerical experiments for the 1994 Hokkaido earthquake (Cho et al., 1995).

Five modes of moment release are examined in the numerical experiments. The modes are identical in mechanism, in scalar moment and in rupture velocity. The dip of the fault plane of the 1994 Hokkaido earthquake is steep, according to Katsumata et al. (1995). Then, we adopted the steep nodal plane as the fault plane: (strike/dip/slip $)=\left(69^{\circ} / 67^{\circ} / 119^{\circ}\right)$. The value of $\mathrm{M}_{\mathrm{o}}=2.1 \times 10^{21} \mathrm{Nm}$ is adopted as the scalar moment. The rupture velocity is assumed to be $2.5 \mathrm{~km} / \mathrm{s}$ according to Kikuchi and Kanamori (1995).

We assume a line source of $120 \mathrm{~km}$ long along the strike direction. The line source is approximated by a linear alignment of point sources at an interval of $20 \mathrm{~km}$. Each point source has a moment of $0.35 \times 10^{21} \mathrm{Nm}$. Hence the moments of the six point sources total $2.1 \times 10^{21} \mathrm{Nm}$. We define a mode of moment release based on Kikuchi and Kanamori (1995), and refer to it as the KK mode in the following. In the KK mode, the initial moment release occurs between the two point sources at the northeast edge of the line source. The moment release propagates in both directions to the edges. The unilateral and bilateral modes are defined as follows: the initial moment release occurs at the northeast edge of the line source and the moment release propagates to the other edge (unilateral); the initial moment release occurs at the center of the line source and the moment release propagates in both directions (bilateral).

The other two modes are defined as follows. We assume a straight line source of $60 \mathrm{~km}$ long along the dip direction. The line source is approximated by putting a point source at the center of every $20 \mathrm{~km}$ line segment. Each point source has a moment of $0.7 \times 10^{21} \mathrm{Nm}$. Hence the moments of the three point sources total $2.1 \times 10^{21} \mathrm{Nm}$. The initial moment release occurs at the lower edge and the moment release propagates to the upper edge in the upward mode. In the downward mode the initial moment release occurs at the upper edge, and the moment release propagates to the lower edge.

Since the moment release propagates at a constant velocity of $2.5 \mathrm{~km} / \mathrm{s}$, the interval time of moment release between adjacent point sources is $8 \mathrm{~s}$. The source durations of the KK mode, the unilateral mode and the other three modes are $40 \mathrm{~s}, 48 \mathrm{~s}$ and $24 \mathrm{~s}$, respectively. The unilateral mode is the longest in both space and time, and the KK mode is the next.

We calculate synthetic ground motions excited by each point source for the given mechanism. Each of these calculations is repeated for every station. The synthetic data are calculated by a summation of all Green's functions, and compiled in the same manner as in the data analyses. We use MMA and TMR in the two station case. In order to stabilize the solution, hypothetical stations A1 and A2 are added (Fig. 2). In the three station case, we use the synthetic data 
sets for the network of A1, A2 and MMA. We examine the instability due to the sparse station coverage by comparing the results in the two station case with the results in the three station case.

Any network of seismographs deployed in the Japanese Islands can not completely surround the earthquakes that occur in the neighboring sea. To remove the problem of the station coverage, hypothetical stations should be located in the ocean. The stations $\mathrm{A} 1$ and $\mathrm{A} 2$ are prerequisite in order to discuss simply the influence of source finiteness on the inversion, though presumably there will be no stations installed there. Numerical experiments for earthquakes in the neighboring sea using hypothetical 10 stations in the Japanese Islands are described in Fukushima et al. (1987, 1989).

The inversion is done in the same manner as the data analysis. The event location is fixed at the centroid of each mode. Figure 8 illustrates the results of the numerical experiments. The true mechanism of the unilateral and the bilateral modes is not retrieved in the two station case, while it is well retrieved in the three station case. The true moment is underestimated for every mode. The ratio of the inverted moment to the true moment ranges from 38 to $95 \%$. The underestimation is slightly reduced in the three station case. The CLVD components in the two station case are larger than those in the three station case.

Next we examine the possibility of reducing the influences of source finiteness. The lower limit of the period range is changed from 70 to $180 \mathrm{~s}$. We carry out the same numerical experiments except for the period range. The results are shown in Fig. 9. The mechanism retrievals of the unilateral and the bilateral modes have improved. Nonetheless, the CLVD components of all modes are considerably large in the two station case. The moment underestimation is reduced, in particular for the $\mathrm{KK}$ and unilateral modes. The ratios of the inverted moment to the true moment are summarized in Fig. 10.

The synthetic seismograms show good fits for every inversion with both period ranges as compared with the data analysis. The RMS averages $10.5 \times 10^{-11}\left[\mathrm{~m}^{2} / \mathrm{s}^{3}\right]$ in Fig. 4 . Figure 11 shows that the residuals in the numerical experiments are much smaller than that in the data analysis. We find that the residuals of the KK and the unilateral modes are

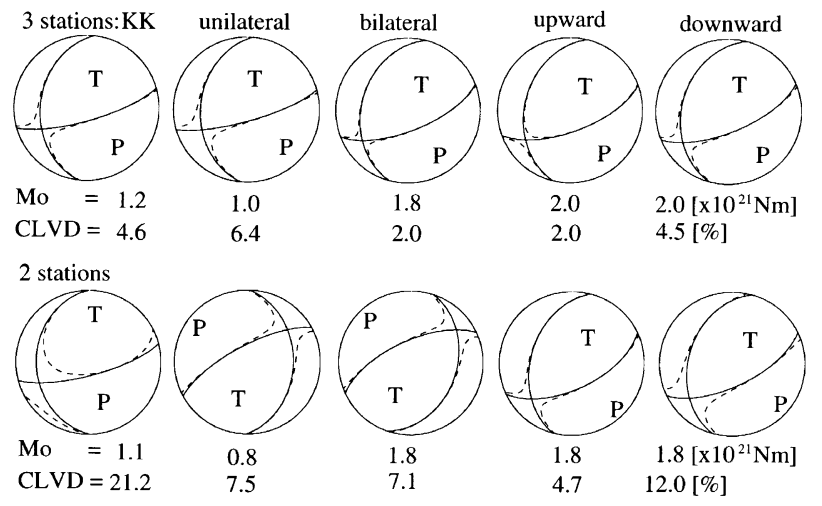

Fig. 8. Results of the numerical experiments in the period range from 70 to $360 \mathrm{~s}$. from 3 to 4 times larger than those of the other modes in the period range from 70 to $360 \mathrm{~s}$. But in the period range from 180 to $360 \mathrm{~s}$, the residual gap in the modes is significantly reduced. The decrease of residuals of the KK and the unilateral modes corresponds to the improvement of the moment retrievals by changing the lower limit of the period range from 70 to $180 \mathrm{~s}$. The residuals increase in the three station case as compared with the two station case. In the three station case the solutions are well constrained and endure the influence of source finiteness contained in the synthetic data. Then the fits of the waveforms become worse. The residual ratio of the three station case to the two station case is about 1.5 for every mode in both period ranges.

The numerical experiments for the 1994 Hokkaido earthquake have revealed that the solutions are strongly influenced by source finiteness, in particular, for the KK and the uni-

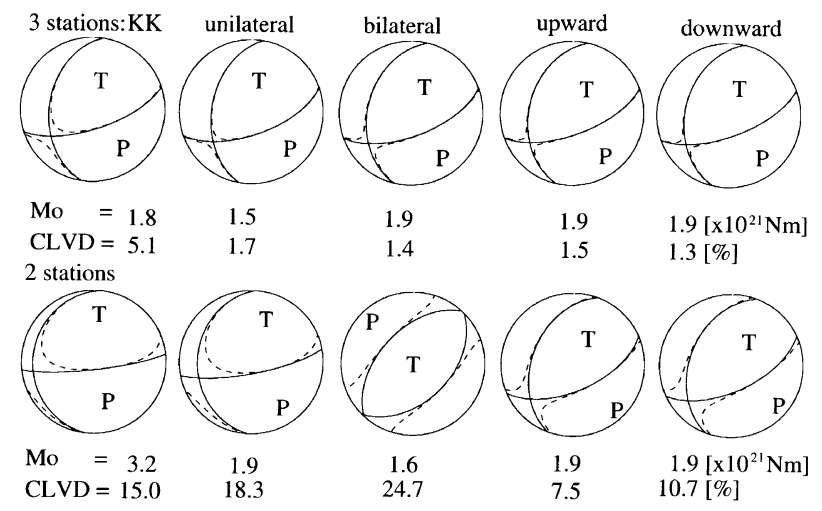

Fig. 9. Results of the numerical experiments in the period range from 180 to $360 \mathrm{~s}$.

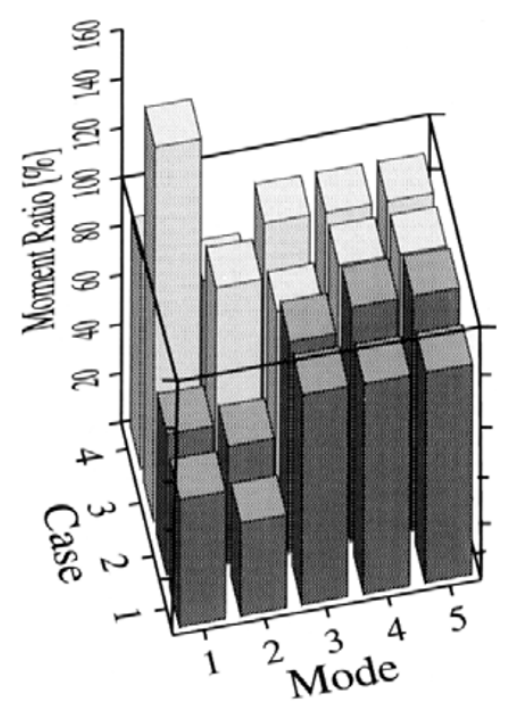

Fig. 10. Ratios of the inverted moment to the true moment. The modes of 1, 2, 3, 4 and 5 correspond to the KK, the unilateral, the bilateral, the upward and the downward modes, respectively. The cases of 1 and 2 (black bars) correspond to the two and three station case with the period range from 70 to $360 \mathrm{~s}$, while the cases of 3 and 4 (white bars) correspond to the two and three station case with the period range from 180 to $360 \mathrm{~s}$, respectively. 
(a)

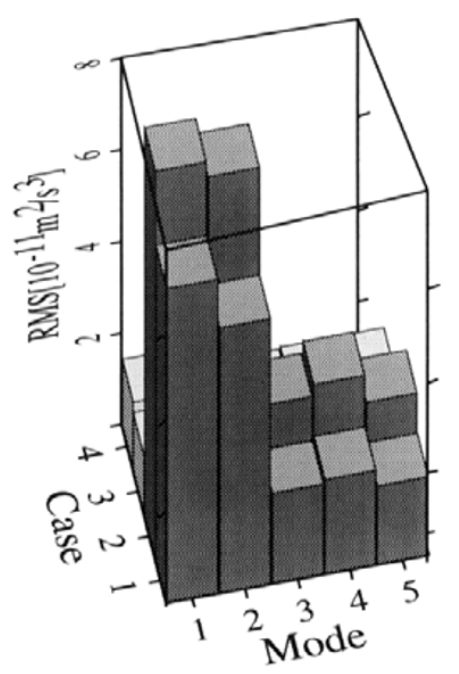

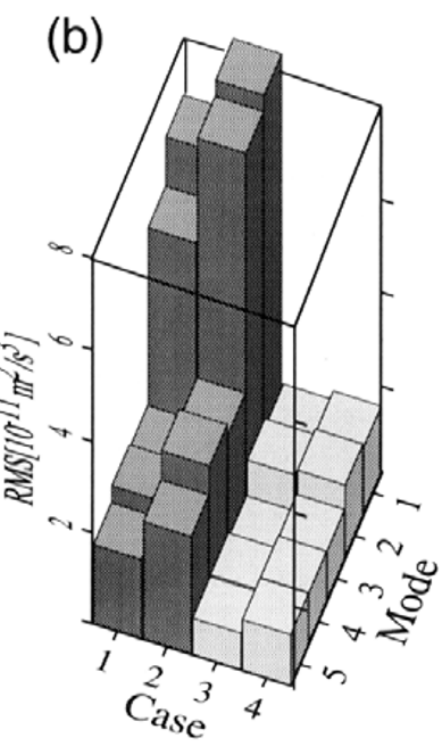

Fig. 11. Average RMS residuals (in $10^{-11} \mathrm{~m}^{2} / \mathrm{s}^{3}$ unit). (a) and (b) represent the same figure viewed from different directions. The cases and modes are the same as Fig. 10 .

lateral modes whose source length and source duration are long. The influence of source finiteness on the moment retrieval is stronger than that on the mechanism retrieval. We can reduce the influence by eliminating short-period components from the data, but the significant increase of the CLVD components in the two station case indicates that the constraints on the solutions are more relaxed than we expected. We have to beware of the station coverage when eliminating short-period components.

\section{Summary}

We have used broad-band, strong-motion data of neardistance large earthquakes for a moment tensor inversion. The solutions are compared with those derived from global data sets. It follows from the comparison that the estimates of the mechanism and moment magnitude are quite adequate.

The numerical experiments reveal that the influence of source finiteness on the moment retrieval is stronger than that on the mechanism retrieval. We only investigate one event in the numerical experiments, and we can thus not easily generalize the results. Nonetheless, the results would exhibit the main feature of the influence of source finiteness, because we assume an ideal case of the station coverage.

The estimation of the centroid of the 1994 Hokkaido Tohooki earthquake would be influenced by the insufficient station coverage. The numerical experiments suggest that the insufficient station coverage also prevents us from reducing the influence of source finiteness by filtering out short-period components from the data. Recently networks of strongmotion seismographs have been installed in the Japanese Islands, but those strong-motion seismographs do not cover the long-period range required for the CMT inversion. The use of the period ranges of these strong-motion seismographs would enhance the problem of source finiteness when a target earthquake is large. To record the large earthquake for the CMT inversion at near distance the system of seismographs should be characterized by not only a wide dynamic range but also a wide period range.

Acknowledgments. We used HITAC M682H at the Hokkaido University Computing Center. This study was supported in part by Japan Society for the Promotion of Science. This study was also partly sponsored by Kansai Research Foundation for Technology Promotion.

\section{References}

Buland, R. and F. Gilbert, The theoretical basis for the rapid and accurate computation of normal mode eigenfrequencies and eigenfunctions, Unpublished Research News, Univ. of Calif., San Diego, 1976.

Cho, I., I. Nakanishi, K. Imanishi, and T. Sato, The CMT solution of the 1994 October 4 Shikotan Islands earthquake $\left(M_{\mathrm{JMA}}=8.1\right)$ recorded by broad-band strong-motion seismographs, Zisin (J. Seism. Soc. Japan), Ser. 2, 48, 353-364, 1995 (in Japanese with English abstract and figure captions).

Dziewonski, A. M. and J. H. Woodhouse, An experiment in systematic study of global seismicity: centroid-moment tensor solutions for 201 moderate and large earthquakes of 1981, J. Geophys. Res., 88, 3247-3271, 1983.

Dziewonski, A. M., T.-A. Chou, and J. H. Woodhouse, Determination of earthquake source parameters from waveform data for studies of global and regional seismicity, J. Geophys. Res., 86, 2825-2852, 1981.

Dziewonski, A. M., G. Ekstrom, and M. P. Salganik, Centroid-moment tensor solutions for July-September 1993, Phys. Earth Planet. Inter., 83, 165-174, 1994.

Dziewonski, A. M., G. Ekstrom, and M. P. Salganik, Centroid-moment tensor solutions for October-December 1994, Phys. Earth Planet. Inter., 91, 187-210, 1995.

Fukushima, T., D. Suetsugu, and I. Nakanishi, Rapid moment tensor inversion of earthquakes near Japan for tsunami warning: Numerical experiments, Zisin (J. Seism. Soc. Japan), Ser. 2, 40, 365-375, 1987 (in Japanese with English abstract and figure captions).

Fukushima, T., D. Suetsugu, and I. Nakanishi, Single station moment tensor inversion for near earthquakes, J. Phys. Earth, 36, 125-133, 1988.

Fukushima, T., D. Suetsugu, I. Nakanishi, and I. Yamada, Moment tensor inversion for near earthquakes using long-period digital seismograms, $J$. Phys. Earth, 37, 1-29, 1989.

Gilbert, F. and A. M. Dziewonski, An application of normal mode theory to the retrieval of structural parameters and source mechanisms from seismic spectra, Phil. Trans. Roy. Soc. London, Ser. A, 278, 187-269, 1975.

Hanakago, Y., I. Nakanishi, T. Moriya, and M. Kasahara, Determination of source mechanisms of near earthquakes from long-period seismic waves, 
Zisin (J. Seism. Soc. Japan), Ser. 2, 43, 213-225, 1990 (in Japanese with English abstract and figure captions).

JMA (Japan Meteorological Agency), The Hokkaido Toho-oki earthquake, 1994 (October 4, M8.1), Report of the Coordinating committee for earthquake prediction, 53, Geophysical Survey Institute Ministry of construction, Japan, 51-56, 1995 (in Japanese with English figure captions).

JMA, Kishocho Koho, special issue, No. 5, 1996 (in Japanese).

Katsumata, K., M. Ichiyanagi, and M. Kasahara, Aftershock Distribution of the October 4, $1994 \mathrm{M}_{w} 8.3$ Kurile islands Earthquake in Hokkaido, Japan, Geophys. Res. Lett., 22, 1321-1324, 1995.

Kikuchi, M. and H. Kanamori, The Shikotan earthquake of October 4, 1994 A lithospheric earthquake, Geophys. Res. Lett., 22, 1025-1028, 1995.

Kinoshita, S., Kyoshin net (K-NET), Seism. Res. Lett., 69, 309-332, 1998.

Kinoshita, S., M. Uehara, T. Tozawa, Y. Wada, and Y. Ogue, Recording characteristics of the K-NET95 strong-motion seismograph, Zisin (J. Seism. Soc. Japan), Ser. 2, 49, 467-481, 1997 (in Japanese with English abstract and figure captions).

Knopoff, L. and M. J. Randall, The compensated linear-vector dipole: a possible mechanism for deep earthquakes, J. Geophys. Res., 75, 49574963, 1970.

Muramatsu, I., Development of a broadband velocity type strong motion seismometer and its recording range, Zisin (J. Seism. Soc. Japan), Ser. 2 , 48, 247-256, 1995 (in Japanese with English abstract and figure captions).
Nakanishi, I., 1993 Japan Sea earthquake: Triggered earthquakes, plate boundary, broad-band strong-motion seismograph, Kaiyo monthly, special issue No. 7, Hokkaido Nansei-oki earthquake and tsunami, 6-11, 1994 (in Japanese).

Nakanishi, I., Y. Hanakago, T. Moriya, and K. Kasahara, Performance test on long-period moment tensor determination for near earthquakes, Geophys Res. Lett., 18, 223-226, 1991.

Noda, S. and H. Kano, Hypocenter estimation system for earthquake countermeasure, J. Nat. Disas. Sci., 15, 53-90, 1993.

Usami, T., Materials for Comprehensive List of Destructive Earthquakes in Japan, pp. 416-1995 (revised and enlarged edition), University of Tokyo Press, 1996 (in Japanese).

Wielandt, E. and J. M. Steim, A digital very-broad-band seismograph, Annales Geophysicae, 4, B, 3, 227-232, 1986.

Wielandt, E. and G. Streckeisen, The leaf-spring seismometer: design and performance, Bull. Seism. Soc. Am., 72, 2349-2367, 1982.

Yamada, I., Y. Fukao, Y. Ishihara, and H. Aoki, Broad-band and wide dynamic range seismic observation by an STS-seismograph, Zisin (J. Seism. Soc. Japan), Ser. 2, 42, 21-31, 1989 (in Japanese with English abstract and figure captions).

I. Cho (e-mail: cho@kugi.kyoto-u.ac.jp), I. Nakanishi, and T. Sato 